\title{
DESAFIOS PARA A PESQUISA EMPÍRICA EM DIREITO: UMA ANÁLISE A PARTIR DE UMA PESQUISA INDUTIVA SOBRE A PRÁTICA JUDICIAL DO HABEAS CORPUS
}

\author{
Victor Fernando Alves Carvalho ${ }^{1}$
}

\section{Resumo:}

Este trabalho objetiva problematizar desafios próprios da pesquisa empírica em direito, tomando como base uma pesquisa indutiva sobre a efetividade da garantia constitucional do habeas corpus, a partir de acórdãos da Câmara Criminal do Tribunal de Justiça do Estado de Sergipe. Metodologicamente, a pesquisa original buscou romper com o modelo parecerista em direito, conforme literatura de Epstein e King. Assim, este trabalho focaliza o percurso metodológico traçado na pesquisa original, de modo a possibilitar uma reflexão sobre "pontos cegos" a que todo pesquisador deve estar atento na busca de achados válidos sobre a prática judicial dos institutos da dogmática jurídica.

Palavras-chave: Pesquisa empírica em direito; inferências descritivas; pesquisa indutiva; dados judiciais; efetividade de institutos.

\section{CHALLENGES FOR EMPIRICAL LAW RESEARCH: AN ANALYSIS FROM AN INDUCTIVE RESEARCH ON HABEAS CORPUS JUDICIAL PRACTICE}

\begin{abstract}
:
This paper aims to problematize challenges which are inherent to empirical law research, based on an inductive research on the effectiveness of habeas corpus, which took place on judgments of the Criminal Chamber of the Sergipe State Court. Methodologically, the original research sought to break with the peer model in law, according to Epstein and King. Thus, this paper focuses on the methodological path outlined in the original research, in order to allow a reflection about "blind spots" to which every researcher should be alert in the search for valid findings on the judicial practice of the dogmatic institutes.
\end{abstract}

Keywords: Empirical law research; descriptive inferences; inductive research; Court data; institute effectiveness.

\section{Considerações iniciais}

Este trabalho tem como objetivo problematizar desafios da pesquisa empírica em direito, a partir de um caso concreto: uma pesquisa sobre a efetividade da garantia constitucional do habeas corpus. Na pesquisa original, buscou-se averiguar quão efetiva é a garantia constitucional do habeas corpus a partir da análise de dados coletados em

\footnotetext{
${ }^{1}$ Bacharel em Direito pela Universidade Federal de Sergipe (2018) e mestrando pelo Programa de PósGraduação em Direito da mesma instituição. Advogado. E-mail: victorfernandocarvalho@gmail.com
} 
julgamentos de HC no Tribunal de Justiça do Estado de Sergipe. ${ }^{2}$ Entendeu-se por efetividade o que Ferraz Junior (2013, p. 171) chama de eficácia social: a capacidade da norma jurídica de produzir efeitos concretos com vistas à satisfação de objetivos declaradamente visados pelo ordenamento. Portanto, efetividade funcionou na pesquisa como um conceito operacional, do ângulo dogmático, relacionado ao alcance dos fins declaradamente definidos para a norma pelo seu ordenamento.

Foi, então, realizada uma série de recortes, em virtude da evidente impossibilidade de se proceder a um estudo universal. Esses recortes foram: espacial (ações de HC ajuizadas perante a Câmara Criminal do Tribunal de Justiça do Estado de Sergipe) e temporal (ações de HC ajuizadas no mês de janeiro do ano de 2017). Nesses termos, a partir da análise dos dados coletados sobre como foram julgadas as ações de HC na amostra selecionada, bem como sobre quais fundamentos foram invocados pelos impetrantes para o ajuizamento das ações, procurou-se estabelecer inferências descritivas, conforme a metodologia de Epstein e King (2013), a fim de obter dados capazes de indicar o grau de efetividade do habeas corpus, considerado enquanto garantia constitucional, em uma pesquisa, portanto, indutiva.

Foram selecionadas como centrais as variáveis "teor do julgamento" e "fundamentos invocados pelo impetrante". A partir da análise do teor do julgamento das ações, era possível investigar o grau de efetividade da garantia do $\mathrm{HC}$ e, como consequência, o diapasão de legalidade sob o qual a prática judicial do HC estava sendo submetida, sobretudo em face dos crescentes abusos no sistema de justiça criminal noticiados inclusive em pesquisas governamentais, como o INFOPEN. Outrossim, a análise dos fundamentos invocados pelos impetrantes para o ajuizamento das ações de HC permitia identificar os principais gargalos para a proteção da liberdade das pessoas. Afinal, as situações mais judicializadas pela via do HC constituem, em tese, os casos mais frequentes de ofensa à liberdade humana, dada a funcionalidade do $\mathrm{HC}$ no ordenamento jurídico brasileiro, tanto na Constituição Federal quanto no Código de Processo Penal, em proteger o direito de ir e vir.

A amostra final abrangeu um total de 227 ações de habeas corpus, tendo 24 tramitado sob segredo de justiça. Os dados colhidos revelaram um baixo grau de efetividade

\footnotetext{
${ }^{2}$ A pesquisa em si - "O julgamento de habeas corpus no Tribunal de Justiça do Estado de Sergipe e o grau de (in)efetividade da garantia constitucional" - foi apresentada em detalhes no Grupo de Trabalho 35 (processo penal, garantias constitucionais e a sua crítica) do X Congresso Internacional da ABraSD - Associação Brasileira de Pesquisadores em Sociologia do Direito, realizado nos dias 16, 17 e 18 de outubro de 2019, em Recife/PE, conforme lista de resumos aprovados: https:/www.doity.com.br/X-congresso-abrasd/blog/resumosaprovados.
} 
do habeas corpus, representado pelo número elevado de ordens que sequer foram conhecidas $(52,9 \%)$, em virtude de questões formais e contornáveis (p. e. não juntada de documentos do processo originário), e pelo número igualmente elevado de ordens denegadas (42,3\%), significando 95,2\% da amostra em que a utilização do HC revelou-se inócua. As conclusões da pesquisa apontaram para uma prática judicial restritiva e castradora desse instituto, sobretudo se se levam em consideração os dados do mais recente levantamento nacional de informações penitenciárias, os quais indicam patentes violações ao direito de liberdade pelo sistema de justiça criminal (p. e. excesso de prisões provisórias, elevando o estado de Sergipe ao segundo lugar nacional), conforme Santos (2017).

A pesquisa foi realizada no âmbito do Departamento de Direito da Universidade Federal de Sergipe, inspirada por um trabalho anterior (REGINATO; ALVES, 2014), sobre a prática judicial do habeas corpus em Sergipe de 1996 a 2000. A apresentação da pesquisa para a banca de avaliação gerou uma série de reflexões sobre o percurso metodológico traçado, os desafios da pesquisa empírica em direito e os "pontos cegos" do trabalho. São essas reflexões que o presente artigo visa abordar, o que será feito dividindo-o em dois capítulos, além das considerações iniciais e finais: primeiramente, serão apresentadas as principais diretrizes da pesquisa empírica em direito, a partir sobretudo da literatura de Epstein e King (2013); em seguida, serão discutidos desafios concretos da pesquisa empírica em direito a partir do estudo do caso da pesquisa original sobre a prática judicial do habeas corpus, de modo a possibilitar uma reflexão mínima sobre os "pontos cegos" a que todo pesquisador deve estar atento na pesquisa empírica em direito.

\section{Principais diretrizes para a pesquisa empírica em direito}

Uma pesquisa científica somente é confiável na medida em que for replicável por um pesquisador diferente do original. É inquestionável, portanto, que o método da pesquisa esteja claro. "A metodologia utilizada para se chegar a uma determinada conclusão é tão importante quanto a conclusão em si, pois aquela permitirá a confirmação desta e validará o conhecimento produzido" (EPSTEIN; KING, 2013, p. 8). No entanto, as regras de inferência, cujo zelo é indissociável da produção de pesquisas empíricas de qualidade, têm sido ignoradas no campo do direito, de acordo com as constatações de Epstein e King (2013), muito embora sejam respeitadas nas ciências exatas e sociais em geral, chegando a existir, nessas áreas, produção científica específica sobre métodos empíricos e regras de inferência. No direito, não 
só há um desrespeito quando se tenta mobilizar as regras de inferência, como também há pouca produção específica sobre o assunto. O problema consequente é que as conclusões alcançadas nas pesquisas empíricas de pouco rigor metodológico, isto é, de patente desrespeito às regras de inferência, são pouco confiáveis e precisas, o que é grave, em virtude da frequência com que conclusões da pesquisa jurídica impulsionam a criação ou reinvenção de políticas públicas (EPSTEIN; KING, 2013, p. 14). ${ }^{3}$

Uma das principais causas das dificuldades de rigor na pesquisa empírica é atribuída por Epstein e King (2013, p. 15) à formação que os catedráticos de direito recebem. Isso porque:

\begin{abstract}
Enquanto um Ph.D. é ensinado a submeter sua hipótese preferida a todos os testes e fontes de dados concebíveis, procurando todas as evidências possíveis contra sua teoria, um advogado é ensinado a compilar todas as evidências em prol de sua hipótese e desviar a atenção de qualquer coisa que possa ser vista como informação contraditória. Um advogado que trata seu cliente como uma hipótese teria retirada sua licença; um Ph.D. que advoga uma hipótese como um cliente, seria ignorado. Mas quando advogados - como professores de direito - vão de um tribunal para os corredores da faculdade (onde a verdade, e não somente uma determinada versão dela, importa) ${ }^{4}$, é altamente problemático para eles defender teorias e hipóteses como se eles fossem clientes necessitando a melhor representação possível, desprezando competidores ou ignorando-os completamente. Isto porque, na pesquisa empírica, desafiar uma teoria com os melhores argumentos opostos possíveis é o que mais fortifica uma teoria (EPSTEIN; KING, 2013, p. 15, grifo ausente no original).
\end{abstract}

Construir a verdade, portanto, como propõe a ciência, exige respeito a regras de validação de hipóteses, e a hipótese escolhida numa pesquisa somente é validada quando se mantém firme em face de suas opositoras. Isso não acontece na prática da advocacia, em que o profissional é orientado a recolher tudo o que estiver ao seu alcance no sentido de fortalecer sua tese, e não de testá-la. Nesse sentido, o "advogado-pesquisador" recolhe apenas o que lhe é favorável e dificilmente se conscientiza dessa racionalidade ao transportar-se do tribunal para a faculdade de direito.

Quanto à confusão entre a prática profissional do advogado e a produção acadêmica do pesquisador, Nobre (2005, p. 30) concorda que se consolidou no Brasil um modelo parecerista como o padrão de pesquisa em direito:

\footnotetext{
${ }^{3}$ Epstein e King (2013, p. 14-15) observam que suas preocupações sobre a qualidade da pesquisa empírica em direito não se esgotariam, mesmo se as conclusões dessas pesquisas não fossem mobilizadas por instâncias de poder para a promoção de políticas públicas. Afinal, a confiabilidade é uma obrigação da pesquisa científica por si só.

${ }^{4}$ Isso porque, de acordo com Epstein e King (2013, p. 9), as técnicas de persuasão próprias da advocacia se propõem a fornecer uma versão da verdade, ao contrário das regras de inferência pautadoras da pesquisa empírica, que procuram, por sua vez, construir a verdade, não apenas uma versão dela.
} 
[...] o parecer recolhe o material doutrinário, jurisprudencial e os devidos títulos legais unicamente em função da tese a ser defendida. Não recolhe todo o material disponível, mas tão-só a porção do material que vem ao encontro da tese a ser defendida; não procura no conjunto do material um padrão de racionalidade e intelegibilidade, para depois formular uma tese explicativa - que é, para mim, o padrão de um trabalho acadêmico em Direito. Então, no caso paradigmático modelar do parecer, a resposta já está dada de antemão. É um tipo de investigação científica que já possui uma resposta antes de perguntar ao material. Este é o problema. Eu não conseguirei avançar na pesquisa em Direito enquanto já souber a resposta antes de fazer a pergunta ao material, já que, quando tenho a resposta, eu só seleciono do material o que importa para defender o que eu já sei. Sem romper essa lógica, não teremos pesquisa em Direito no Brasil (NOBRE, 2005, p. 30-32, grifo ausente no original).

Segundo Nobre (2005, p. 24-25), a pesquisa em Ciências Humanas no Brasil cresceu vertiginosamente nos últimos trinta anos, tanto em quantidade quanto em qualidade, não tendo o Direito, contudo, acompanhado essa qualidade crescente. A hipótese do autor é que esse atraso está relacionado a) ao isolamento do direito quanto às outras Ciências Humanas e b) à referida confusão entre a prática profissional e a produção acadêmica. Em sua investigação, Nobre destaca que o modelo atual do curso de Direito está fadado à obsolescência e que a ausência do Direito provoca uma deficiência marcante no que ele chama de "consórcio das ciências humanas" (2005, p. 24-25).

Oliveira (s.d., p. 4), em reflexões mais circunscritas à pós-graduação na Sociologia Jurídica, também percebe uma cultura parecerista na produção acadêmica em Direito no Brasil:

[...] tratando-se de uma dissertação ou tese, o autor deverá ter sempre presente no seu espírito que um estudo desse tipo não poderá se confundir com um parecer para defender o interesse de um cliente. Como trabalho acadêmico, ele deverá jungir-se a alguns princípios que o presidem, como o da objetividade e, tanto quanto possível, o da sempre problemática - mas no final das contas e em alguma medida incontornável - neutralidade axiológica. [...] Falando de uma maneira bem simples, uma coisa é um advogado elaborando um parecer, como já disse. Outra coisa é um acadêmico sustentando uma tese. No primeiro caso, a primeira lealdade do parecerista é para com o interesse do seu cliente; já a primeira lealdade do mestrando ou doutorando deverá ser para com a verdade (OLIVEIRA, sem data, p. 4, grifo ausente no original).

Oliveira (s. d., p. 5) destaca que, além da cultura parecerista, os trabalhos acadêmicos em direito têm pecado pela impureza, ao contrário do que seria de se esperar da hegemônica tradição kelseniana nos cursos de direito. Tem sido comum, assim, que nos textos de direito sejam feitas incursões na sociologia (bem como na história e na filosofia) que não passam de discursos opiniáticos, fundamentados no senso comum, que arrematam em exortações genéricas à mudança social, fugindo, assim, do rigor das ciências empíricas. O problema central dessa postura "impura" é que, ao fazer incursões em outras áreas do saber, o 
pesquisador do direito dificilmente conhece as exigências metodológicas da outra área e os referenciais teóricos que inconscientemente mobiliza.

O autor dá dois exemplos (s. d., p. 11): um sobre uma pesquisa em justiça tributária, na qual o pesquisador afirma que já entre os egípcios se falava em contribuições às despesas públicas proporcionalmente às capacidades de cada indivíduo, o que também se verificou na Roma Antiga, culminando no Brasil de 1988; outro sobre uma pesquisa em lesão contratual, na qual o pesquisador afirma que a teoria da imprevisão, existente na legislação brasileira atual, havia sido concebida no Código de Hamurábi. Em ambos os casos, os pesquisadores do direito fazem incursões no campo da história, estando inconscientes, contudo, de que, ao defenderem que ideia tal já estava presente no passado de forma embrionária, estão se posicionando na corrente evolucionista da história, em completo desuso pelos historiadores contemporâneos. Resumo da ópera: essas pesquisas seriam - legitimamente - questionadas por qualquer historiador que as lesse.

Além da cultura parecerista e da impureza discursiva, se destaca o que Oliveira chamou de manualismo: "a tendência a escrever na dissertação ou tese verdadeiros capítulos de manual, explicando redundantemente [...] o significado de princípios e conceitos que são como que o bê-á-bá da disciplina” (s. d., p. 6). Com o manualismo, também se faz presente o reverencialismo, a utilização de argumentos de autoridade no sentido de "convencer" acerca da sua tese, como se o pesquisador estivesse num tribunal advogando a causa de um cliente (s. d., p. 7). Ambas as práticas são anticientíficas, sobretudo a segunda, por canalizarem a cultura do parecer e transformarem a dissertação ou tese numa verdadeira peça processual.

Para Oliveira, o manualismo e o reverencialismo contribuem para a difusão da confusão metodológica, tendo em vista que se está no manual da faculdade, de fácil acesso na prateleira, que o "douto fulano de tal, cânone do saber jurídico" afirmou isso ou aquilo, a informação está autorizada e ponto final. O resultado disso é um conjunto de incursões desautorizadas, do ponto de vista das exigências metodológicas e das ferramentas teóricas de cada área do saber, gerando um descrédito das pesquisas do direito diante das outras ciências sociais. O trabalho de Epstein e King (2013), nesse panorama, tem o mérito de adequar as regras de inferência na pesquisa das ciências exatas e sociais às pesquisas empíricas no campo do direito, fornecendo orientações sobre rigor metodológico na observação científica da realidade. 
No Brasil, em publicação dedicada ao tema da pesquisa empírica em direito, Veronese (2013, p. 200) defende que a não consolidação dos métodos empíricos no campo do direito se deve à escassez de sua prática nos programas de pós-graduação. Essa relação de causa e consequência é atestada por meio de um círculo vicioso (2013, p. 199), a partir do qual os pesquisadores do direito não inserem métodos empíricos em sua produção científica, dificultando que os discentes de pós-graduação entrem em contato com pesquisa empírica e introduzam tais técnicas na sua produção, culminando em uma total ausência de contato dos discentes da graduação com as técnicas e os métodos empíricos. "Assim, se a pesquisa empírica não fez parte da formação dos docentes, ela possui baixa possibilidade de ser retransmitida aos graduandos" (VERONESE, 2013, p. 200).

Epstein e King (2013, p. 23) indicam que os realizadores de pesquisa empírica têm em comum a) a busca por um ou mais objetivos específicos: I - coletar dados, para seu próprio uso ou para uso de outros pesquisadores; II - resumir dados, quando for necessário facilitar-lhes a compreensão; III - realizar inferências descritivas ou causais, isto é, a partir dos dados conhecidos, aprender coisas novas sobre os dados não conhecidos e almejados; e b) a necessidade de respeito a determinadas regras gerais para o alcance desses objetivos.

As inferências descritivas e causais também são referidas por Alexandre Samy de Castro (2017, p. 39) como as funcionalidades básicas do método empírico quantitativo. O autor afirma que no Brasil há de modo geral uma deficiência no campo de pesquisas quantitativas sobre o funcionamento das instituições que compõem o sistema de justiça, muito embora se esteja vivendo um contexto de políticas públicas impulsionadas por bases empíricas - as quais, por sua vez, ainda são rudimentares, mais voltadas para interesses específicos de grandes litigantes (CASTRO, 2017, p. 39-40). Também se vive um contexto de digitalização dos registros judiciais, o que gera oportunidades únicas de diagnósticos confiáveis (CASTRO, 2017, p. 40), não apenas para avaliações do impacto prático de reformas legais e institucionais, como também para investigações da prática judicial dos institutos jurídicos, como é o caso da pesquisa original sobre a efetividade do HC.

Ultimamente as pesquisas quantitativas no direito, que utilizam bancos de dados estruturados (como os do CNJ e dos tribunais) e não-estruturados (sentenças judiciais, por exemplo, que precisam ser codificadas/classificadas), têm passado por um processo de expansão (CASTRO, 2017, p. 43), tanto em virtude do desenvolvimento da ciência de dados, quanto por causa da progressiva abertura das fontes de informação (publicação de relatórios 
estatísticos, digitalização dos registros judiciais etc.). No caso de banco de dados nãoestruturados (que é o caso da pesquisa original sobre habeas corpus), é necessário codificar as decisões judiciais por meio das expressões regulares (no caso de amostras maiores, utilizamse métodos automatizados), que passam a constituir variáveis.

Ainda quanto à reflexão em si sobre coleta de dados, é possível a preservação de registros por si só, contudo esse interesse, conforme Epstein e King (2013, p. 24), não tem pertencido à escola empírica, que busca coletar dados de modo que possam ser mobilizados para algum outro fim. A coleta de dados, portanto, não costuma se encerrar em si mesma; o pesquisador costuma ter em mente outros objetivos a partir da coleta ${ }^{5}$, tais como resumir dados ou fazer inferências.

Vale destacar, ainda conforme Epstein e King (2013, p. 28), que nem sempre os dados com que o pesquisador opera são obtidos de outras fontes. Os dados podem ser gerados pelo próprio pesquisador, a partir de questionários, entrevistas e experimentos. De todo modo, como já dito, a coleta de dados não costuma ser um fim em si mesmo na pesquisa empírica. Conforme Epstein e King (2013, p. 28), independentemente do objetivo da coleta de dados (resumi-los ou fazer inferências descritivas ou causais a partir deles), o processo de coleta deve ser registrado passo a passo, em toda a sua inteireza, e quanto mais dados, melhor para a pesquisa.

Resumir os dados coletados, por sua vez, é útil quando a quantidade de dados está além da percepção direta da maioria das pessoas, conforme Epstein e King (2013, p. 30) esclarecem. Assim, se for inviável, pela quantidade de dados obtidos, interpretá-los simultaneamente, é mais favorável apresentá-los em resumo do que em sua forma bruta. O resumo, portanto, se apresenta como um mecanismo de facilitação daquilo que os dados podem comunicar ao leitor.

Quando se trata de dados numéricos, seu resumo exige atividades de cunho estatístico. As mais simples consistem na apresentação da média, mediana, moda, intervalo e desvio padrão (EPSTEIN; KING, 2013, p. 30). A média, a mediana e a moda são medidas de

\footnotetext{
5“'Entretanto, há exceções, principalmente a chamada base de dados 'multiusuário' ou 'de uso público'. A ideia por trás de tais bancos de dados é direta o suficiente: em vez de coletar dados para responder a uma determinada pergunta de pesquisa - por exemplo, em quantos casos capitais há erros? - coletar grandes bancos de dados tão ricos em conteúdo que múltiplos usuários, mesmo aqueles com projetos distintos, podem utilizá-los" (EPSTEIN; KING, 2013, p. 25). Além de as bases de dados "multiusuário" servirem simultaneamente a vários grupos de pesquisa com projetos diferentes, elas também apresentam uma "vantagem combinatória" (EPSTEIN; KING, 2013, p. 25), que fica visível nas tabulações cruzadas.
} 
tendência central, aptas a informar o centro de distribuição dos dados: a média é simples e representa a quantidade média dos dados; a mediana é o caso localizado no ponto central da distribuição; a moda é o caso que aparece com mais frequência. O intervalo e o desvio padrão, por sua vez, caracterizam-se como medidas de dispersão, aptas a informar em que medida os valores variam em relação aos valores típicos. O intervalo representa o espaço entre o valor mínimo e o máximo, ao passo que o desvio padrão representa uma estatística da distância entre cada valor e a média dos valores.

Apresentar o resumo dos dados em representação gráfica é oportuno (EPSTEIN; KING, 2013, p. 31). Ademais, o resumo dos dados não necessariamente precisa ser apresentado em forma tabular, por existirem outras técnicas igualmente válidas, como o histograma (gráfico de barras). Além disso, os autores chamam atenção para a necessidade de o pesquisador não reificar seus dados no momento de apresentar um resumo, o que ocorre com frequência quando o jurista deseja apresentar "perfis", "médias" - criações do pesquisador que não necessariamente refletem com precisão os dados -, no lugar de buscar resumir os componentes da coleta:

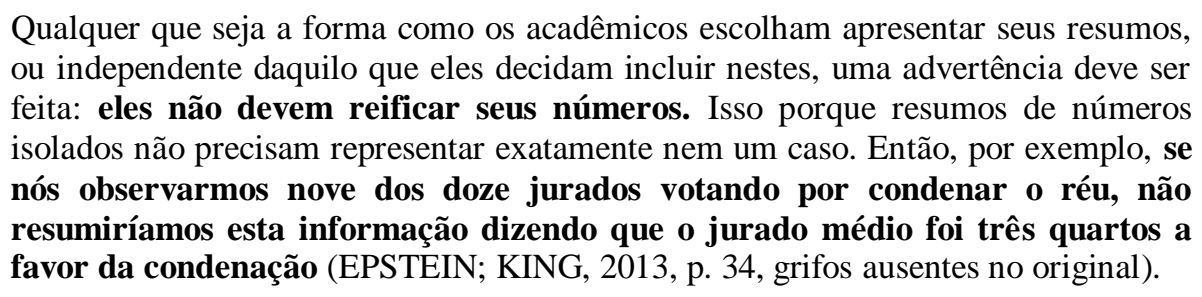

De fato, o resumo dos dados fornece uma descrição da observação dos fenômenos. $\mathrm{O}$ objetivo, porém, pode ir além: fazer inferências - mobilizar os fatos conhecidos para aprender sobre os fatos não conhecidos. Essas inferências são descritivas ou causais. "Enquanto os pesquisadores costumam utilizar resumos de dados para fazer inferências descritivas, inferências descritivas", contudo, "são diferentes de resumos de dados" (EPSTEIN; KING, 2013, p. 36).

O objetivo da inferência descritiva é mobilizar os fatos conhecidos para aprender sobre fatos ainda não conhecidos. Epstein e King (2013, p. 36-37) dão o exemplo de uma pesquisa que buscava investigar, com foco no Japão, o que levava o crime organizado a surgir e que papel tinha essa modalidade de crime na economia. Eles coletaram e resumiram dados sobre o Japão de 1972 a 1997 e, com base nos dados coletados e resumidos, intentavam aprender sobre o crime organizado no Japão de um modo geral e aprender sobre o crime organizado em outras regiões, como a Rússia e Sicília. Assim, os fatos conhecidos 
(experiência japonesa quanto ao crime organizado no período de 1972 a 1997) foram mobilizados para aprender sobre fatos não conhecidos, mas almejados (crime organizado no Japão de modo geral e crime organizado em outros países - duas inferências descritivas). Tem-se, assim, uma pergunta genérica, cuja resposta recebe a contribuição de uma amostra específica como ponto de partida. Tenta-se, a partir das observações coletadas num país num período determinado de tempo, aprender algo sobre o país de um modo geral, e não apenas no lapso temporal mobilizado (EPSTEIN; KING, 2013, p. 37). Isso é uma inferência descritiva.

\begin{abstract}
Ao mesmo tempo, estão procurando generalizar sobre o mundo baseados em testes em uma pequena parte dele. Isto é, eles querem aprender algo sobre os outros países, outras cortes [referência à investigação de Lederman] ou outros períodos de tempo, os quais eles não estão observando. Os fatos que eles não observam ou conhecem são por vezes chamados características de uma população (por exemplo, todos os países de interesse, incluindo o Japão), os valores sobre os quais estão buscando aprender através da mensuração de uma amostra (por exemplo, o Japão nos anos de 1972 até 1997). [...] o primeiro passo crítico para traçar uma inferência descritiva é identificar o alvo da inferência - o fato que gostaríamos de conhecer, como o crime organizado em todos os países ou os acordos em todos os casos (EPSTEIN; KING, 2013, p. 37-38, grifo ausente no original).
\end{abstract}

Identificando com clareza o alvo da inferência, estabelecendo com precisão a população e a amostra mensurada, críticas dispensáveis à pesquisa podem ser evitadas, como a amostra selecionada para mensuração ser pouco representativa da população (EPSTEIN; KING, 2013, p. 38). O alvo da inferência precisa estar bem especificado:

Cabe aos pesquisadores, e não aos leitores, especificar o objeto de sua inferência.
Caso este objeto seja esquivo ou obscuro para os investigadores, o que eles
devem fazer é imaginar como procederiam com um orçamento ilimitado e sem
limites sobre a quantidade de tempo e esforço que poderiam despender. Se,
nessa situação hipotética, eles descobrirem que são incapazes de esclarecer com
grande precisão a quantidade a ser estimada, eles devem repensar o projeto em seus
estágios anteriores, se não do zero. De fato, sem um objeto identificado e não-
ambíguo, um projeto de pesquisa não poderá ser razoavelmente avaliado e,
portanto, não poderá ser bem-sucedido (EPSTEIN; KING, 2013, p. 39, grifos
ausentes no original).

Deve-se ter cuidado, outrossim, para não fazer inferências a partir de uma amostra pouco representativa (uns casos "chave" - string citations - ou uma análise mais profunda de um único caso "chave"). Devem sempre estar explícitas as tentativas de inferência descritiva, no sentido de a amostra colhida ser representativa da população, de ficar claro qual seria o significado de "representativo" no contexto da pesquisa e de ser palpável que os casos selecionados estariam aptos a representar quaisquer casos que não os escolhidos (EPSTEIN; KING, 2013, p. 40). Essas providências evitam que a pesquisa induza o leitor em erro, de modo que os casos selecionados para a pesquisa sejam efetivamente exemplares da 
população, e não apenas os mais visíveis ao pesquisador. Para que as inferências descritivas tenham um maior grau de precisão,

\begin{abstract}
[...] [os pesquisadores] precisam revelar muito mais sobre o processo pelo qual eles geraram e observaram seus dados - todo o processo, do momento em que $o$ mundo gerou o fenômeno de interesse até o momento em que os dados estavam em sua posse e foram considerados definitivos (EPSTEIN; KING, 2013, p. 42, grifo ausente no original).
\end{abstract}

Assim, se as decisões referentes à seleção dos casos forem detalhadamente reveladas pelo pesquisador, o leitor terá condições de medir o grau de representatividade da amostra em face da população e poderá avaliar a qualidade das inferências tentadas (EPSTEIN; KING, 2013, p. 42). O renome do investigador é irrelevante para definir a validade das inferências: "somente a evidência - o processo pelo qual os dados foram observados, e não a fama, trabalho, status ou renda do investigador - é conteúdo da inferência científica feita com seriedade" (EPSTEIN; KING, 2013, p. 42-43).

Ainda sobre as inferências, outro tipo que se pode obter com a pesquisa empírica é a inferência causal. Segundo Epstein e King (2013, p. 43-44), nos estudos causais o pesquisador deseja entender se uma variável dá causa a algum resultado (por exemplo, se a edição da Lei Seca diminuiu o número de acidentes de trânsito motivados por embriaguez ao volante). Nesse tipo de pesquisa, trabalha-se com uma variável causal principal (no exemplo dado, a edição da Lei Seca) aliada a uma variável dependente (possíveis eventos e resultados - no caso, se a Lei Seca aumentou, diminuiu ou não afetou o número de acidentes de trânsito causados por embriaguez ao volante).

No fim das contas, "uma inferência causal é a diferença entre duas inferências descritivas" (EPSTEIN; KING, 2013, p. 45). Recuperando o exemplo dado (Lei Seca), é indispensável ao pesquisador aprender sobre duas realidades diferentes: a realidade dos acidentes de trânsito por embriaguez ao volante antes da Lei Seca e a realidade dos acidentes de trânsito por embriaguez ao volante depois da Lei Seca. Assim, a diferença entre essas duas realidades permite identificar o efeito causal - que é o objetivo da inferência causal: saber em que grau a variável "Edição da Lei Seca" interferiu nessa realidade. Há, porém, um desafio adicional para a pesquisa causal (EPSTEIN; KING, 2013, p. 45): trata-se do "problema fundamental da inferência causal", representado pela impossibilidade de os efeitos da existência de uma variável causal e da sua não existência serem simultaneamente verificados sobre a unidade investigada. No exemplo dado, é impossível verificar ao mesmo tempo as 
duas realidades estudadas: acidentes por embriaguez ao volante sem a Lei Seca e acidentes com a Lei Seca (após a data da entrada em vigor da Lei).

Por fim, Epstein e King (2013, p. 47) indicam que algumas diretrizes devem ser sempre respeitadas, independentemente do objetivo do pesquisador. Em primeiro lugar, a pesquisa deve ser replicável, isto é, quem a acessa deve poder avaliá-la sem quaisquer informações adicionais. Obedecendo ao padrão de replicação, a pesquisa torna-se autossuficiente, e sua legitimidade científica sobrepõe-se a simplórios argumentos de autoridade. Ademais, os procedimentos escolhidos influenciam diretamente os resultados da pesquisa: se esses procedimentos forem enviesados, não se saberá como interpretar os resultados obtidos. No mesmo sentido, deve-se considerar a pesquisa empírica como um empreendimento social de aprender sobre o mundo, sendo relevante não o autor, mas sim sua contribuição à literatura acadêmica. Por fim, é preciso admitir que toda pesquisa terá um grau de incerteza, pois é impossível verificar completamente a realidade que se almeja conhecer (EPSTEIN; KING, 2013, p. 63). O ideal, portanto, é que o pesquisador saiba estimar esse grau de incerteza, para não enfraquecer o potencial das suas inferências.

\section{Reflexão sobre os "pontos cegos" da pesquisa empírica: caso da pesquisa indutiva sobre a efetividade do habeas corpus}

O desafio da pesquisa original era produzir um trabalho que pudesse se situar no marco da ruptura relativamente ao modelo parecerista criticado no capítulo anterior, em um exercício de pesquisa empírica, para assim criar um banco de dados sobre julgamentos de habeas corpus pelo Tribunal de Justiça do Estado de Sergipe que pudesse servir de parâmetro para investigações sobre o grau de efetividade em geral da aludida garantia constitucional.

Pelo fato de os acórdãos do Tribunal de Justiça do Estado de Sergipe constituírem um banco de dados não-estruturados, era necessário codificar os julgamentos por meio das expressões regulares: as variáveis, cujo exame possibilitou refletir sobre o olhar com o qual os Desembargadores do Tribunal analisam um pedido de habeas corpus. A chave da pesquisa era identificar esse olhar, pois o que estava contido nele - uma cultura mais garantista, ou excessivamente formalista, ou corporativista - informava no fim das contas sobre o alcance da garantia do habeas corpus.

Assim, as informações constantes nos registros eletrônicos do TJSE não estavam sistematizadas, como é comum não estarem nos websites dos Tribunais, afinal "[...] a 
interface de consulta processual não foi desenhada para fins de pesquisa jurídica, mas sim para consultas avulsas por parte de entes diretamente envolvidos na lide" (CASTRO, 2017, p. 47). Por essa razão, o primeiro desafio da pesquisa era sistematizar essas informações, criando um banco de dados, o que seria facilitado se houvesse uma preocupação mais clara por parte dos Tribunais com relação a como constituem seus bancos de dados e como registram suas ementas, já que em geral as palavras-chave das ementas é que vão permitir a fixação da amostra.

A amostra selecionada na pesquisa original foi obtida pelo seguinte procedimento: no website de consulta processual do Tribunal de Justiça do Estado de Sergipe, selecionou-se a aba "processos distribuídos", que aparece assim:

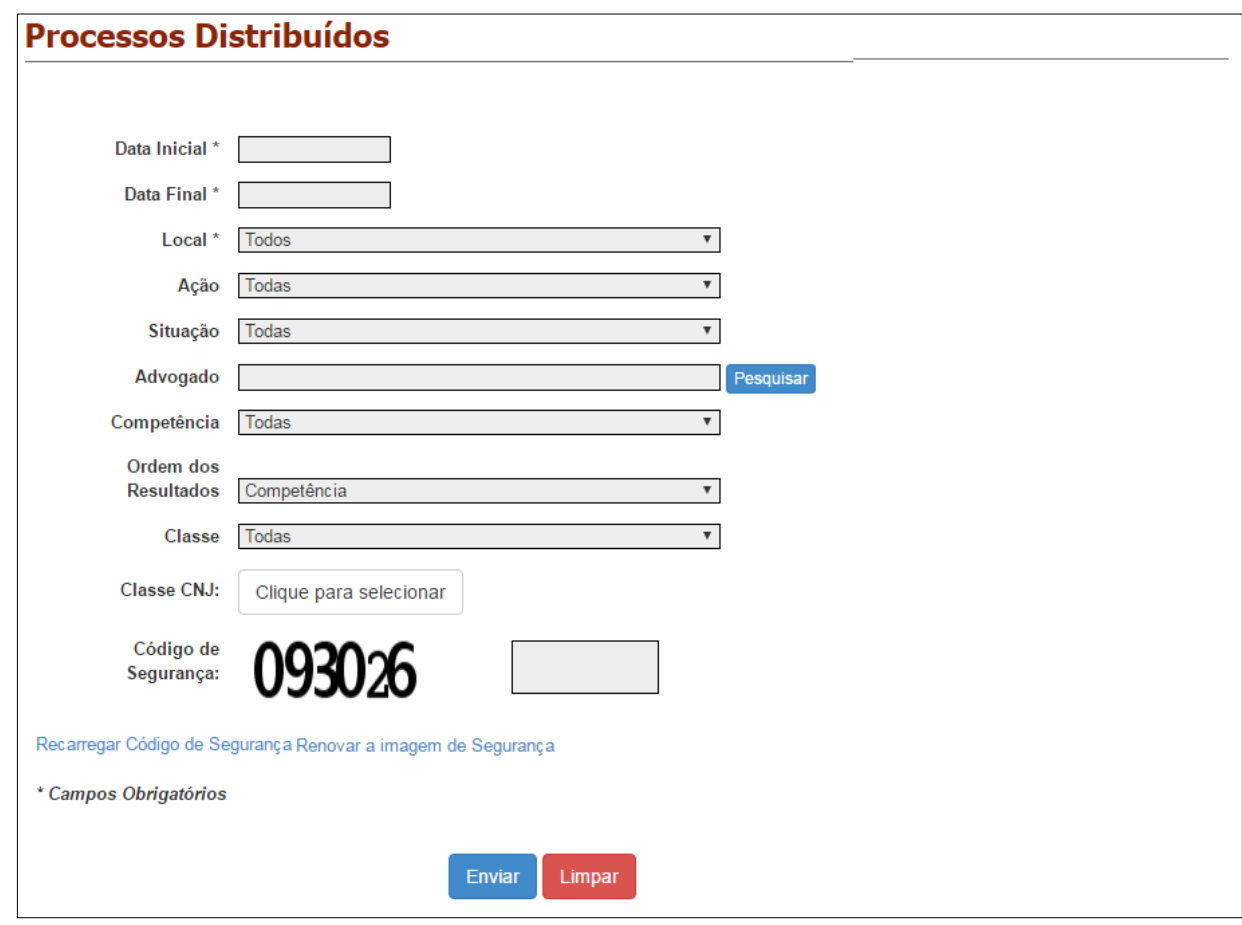

Nos espaços "data inicial" e "data final", dividiu-se a amostra em quatro momentos: 01.01.2017 - 08.01.2017; 09.01.2017 - 16.01.2017; 17.01.2017 - 24.01.2017; 25.01.2017 31.01.2017; tendo em vista que a consulta pública sem filtro de "advogado" somente permitia um recorte temporal de no máximo uma semana. ${ }^{6}$ No campo "local", selecionou-se, dentre as opções "Todos", "Primeiro Grau", "Segundo Grau", "Turma Recursal” e "Juizados Especiais", a terceira alternativa. No campo "ação", selecionou-se, dentre as opções "Todas", "Cível" e "Criminal", a terceira alternativa. No campo "situação", dentre as opções "Todas",

${ }^{6}$ Como o projeto foi executado em 2018, o propósito inicial da pesquisa era cobrir todo o ano de 2017, contudo limitações de recurso e tempo impediram sua conclusão, razão por que se decidiu por cobrir pelo menos os primeiros habeas corpus do ano, no caso impetrados no mês de janeiro. 
"Andamento" e "Julgado", selecionou-se a primeira alternativa. No campo "advogado", não foi estabelecido filtro.

No campo "competência", por sua vez, dentre as opções "Todas", "Tribunal Pleno", "Câmara Cível”, "Câmara Criminal", "Conselho Magistratura”, "Tribunais Superiores" e "Câmaras Cíveis Reunidas", selecionou-se a primeira alternativa, e não a quarta, tendo em vista que as ações de HC são distribuídas não para a Câmara Criminal, mas sim para o Gabinete do Desembargador que é selecionado, por sorteio eletrônico, como Relator. Nesse caso, não se correu o risco de que o recorte pela competência (Câmara Criminal) fosse desrespeitado, afinal as ações de habeas corpus eram necessariamente distribuídas para os Gabinetes dos Desembargadores componentes da aludida Câmara. Por fim, quanto ao campo “ordem dos resultados", entendeu-se como indiferente, pois de qualquer modo todas as ações da amostra selecionada seriam analisadas, e quanto ao campo "classe" selecionou-se por óbvio a opção "habeas corpus".

Nesses termos, o material selecionado a partir de um recorte espacial (ações de habeas corpus impetradas perante o Tribunal de Justiça do Estado de Sergipe) e de um recorte temporal (ações de habeas corpus impetradas no mês de janeiro do ano de 2017) totalizou uma amostra de 227 ações de HC, das quais 24 tramitaram em segredo de justiça. Em seguida, o material foi categorizado segundo o teor do julgamento e os fundamentos invocados pelos impetrantes. A intenção era que a pesquisa permitisse compreender em que parâmetros a garantia do habeas corpus era admitida pelo Tribunal de Justiça do Estado de Sergipe e, a nível mais profundo, se o HC efetivamente cumpria seu papel constitucional de contenção da violência ínsita ao poder de punir do Estado. 


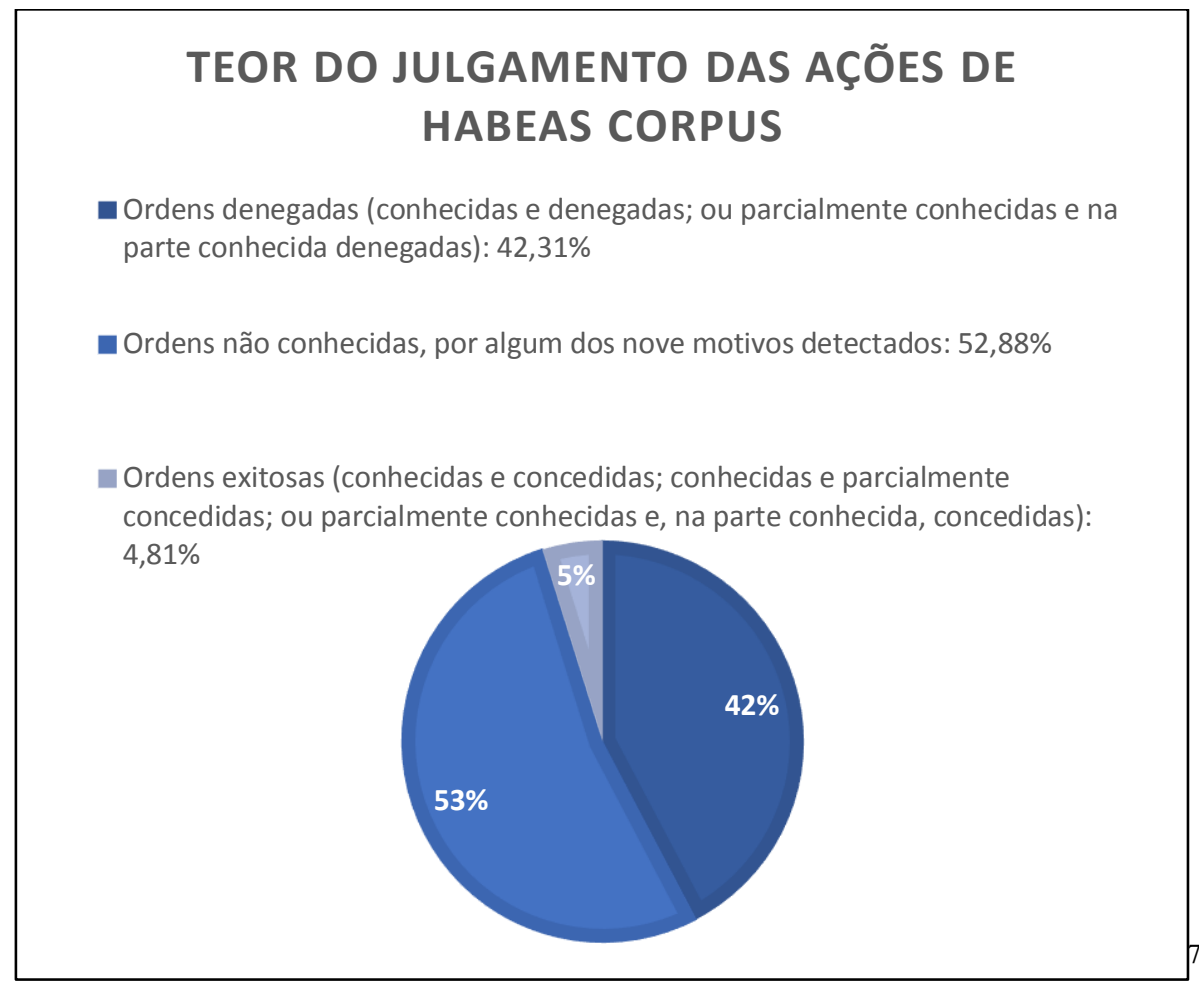

Os dados colhidos (gráfico acima) revelaram um baixo grau de efetividade do habeas corpus, representado pelo número elevado de ordens que sequer foram conhecidas $(52,9 \%)$, em virtude de questões formais e contornáveis (p. e. não juntada de documentos do processo originário), e pelo número igualmente elevado de ordens denegadas (42,3\%), significando 95,2\% da amostra em que a utilização do HC revelou-se inócua.

Quanto aos argumentos dos pedidos, vinte e duas questões foram identificadas como causas de pedir invocadas pelos impetrantes nas ações de habeas corpus. Dessas vinte e duas questões, apenas a ausência dos requisitos necessários à prisão preventiva $(45,95 \%)$ e o excesso de prazo na formação da culpa $(18,53 \%)$ são responsáveis por quase dois terços de todas as ocorrências. Afirmou-se, assim, que esses percentuais revelam a existência de dois sérios gargalos no sistema constitucional de proteção à liberdade humana: a decretação excessiva de prisões preventivas ilegais e a manutenção demorada dessas prisões sem que haja um julgamento definitivo da ação penal.

Essas foram as conclusões da pesquisa original, isto é, as inferências descritivas que se pretendeu realizar. Aprendendo sobre como os Desembargadores do Tribunal de Justiça do

\footnotetext{
${ }^{7}$ Nove motivos apresentados pela Câmara Criminal para impedir o conhecimento do mérito do habeas corpus: incompetência; estreiteza da via e inadequação do HC como sucedâneo recursal; desistência; falta de interesse processual; coisa julgada; falta de prévia análise da autoridade inferior e consequente possibilidade de supressão de instância; falta de objeto; ausência de prova pré-constituída; litispendência.
} 
Estado de Sergipe tratavam os pedidos de habeas corpus (realidade menor), buscou-se aprender sobre quão efetivo é o instituto do habeas corpus na tutela da liberdade das pessoas (realidade em geral). No caso, inferiu-se que o instituto é pouco efetivo e que a prática judicial do habeas corpus neutraliza suas potencialidades, reproduzindo padrões históricos do Brasil Imperial investigados por Koerner (1999). No entanto, a credibilidade dessa inferência é ponderada por algumas margens de incerteza que não foram identificadas ao longo da pesquisa original, somente depois, com a apresentação dos resultados para uma banca de avaliação.

O presente trabalho foi pensado exatamente para discutir esses "pontos cegos", de modo a possibilitar uma reflexão e autorreflexão sobre o grau de comprometimento que uma pesquisa empírica de qualidade exige.

Em primeiro lugar, percebeu-se depois uma margem de incerteza quanto aos dados acerca dos argumentos invocados pelos impetrantes dos pedidos de habeas corpus, tendo em vista que os fundamentos foram analisados não a partir das petições iniciais, mas sim a partir dos relatórios constantes nos votos dos Desembargadores Relatores. Contudo, ponderou-se que isso não diminuía a credibilidade dos dados obtidos, tendo em vista que no fim das contas apenas duas variáveis dominaram o campo: a ausência dos requisitos necessários à prisão preventiva $(45,95 \%)$ e o excesso de prazo na formação da culpa $(18,53 \%)$, responsáveis por $64,48 \%$ do total de ocorrências.

Em segundo lugar, como a pesquisa foi realizada no ano de 2018, o propósito inicial era cobrir todo o ano de 2017 junto à Câmara Criminal do Tribunal de Justiça do Estado de Sergipe, com o fito de gerar uma amostra suficientemente representativa da população. Porém, uma contagem preliminar mostrou que todo o ano de 2017 redundaria em mais de dois mil habeas corpus - uma análise que se mostrava inviável para as limitações de recurso e tempo com que o projeto contou. Por essa razão, diminuiu-se o recorte para o primeiro mês do ano de 2017, o que totalizou 227 habeas corpus, amostra que, à época, pareceu satisfatória, sobretudo diante da falta de financiamento para a pesquisa.

Contudo, à época, não se pensou nas consequências de eleger um mês tal qual janeiro, tendo em vista que pode não ser um mês "padrão". Não se procurou investigar se havia Desembargadores de férias; caso sim, quem estava substituindo; mesmo restringindo-se a realidade para janeiro, não se buscou investigar se seria um mês típico em relação a janeiros de outros anos ou mesmo aos outros meses de 2017. Se fosse julho de 2017, haveria alguma 
consequência, por ser um mês de férias? Eventualidades como janeiro ser um mês de plantão, ou outros casos como um mês festivo (Carnaval em fevereiro, São João em junho) acarreta alguma consequência para o comportamento dos Desembargadores? Em sendo janeiro um mês tipicamente de plantão, variáveis como "quem está no plantão naquele dia" seriam estratégicas?

Em terceiro lugar, não houve um acompanhamento das ações até o trânsito em julgado. As ações da amostra foram as impetradas em janeiro de 2017; os julgamentos se deram no decorrer do ano, e certamente alguns acórdãos foram questionados via recurso. $\mathrm{O}$ julgamento do recurso nos tribunais superiores pode ter modificado o teor da decisão, eventualmente garantindo uma efetividade maior ao instituto do que a observada na realidade estadual. A execução do projeto não cobriu esse acompanhamento.

Em quarto lugar, dentre as ordens não conhecidas (52,88\%), havia uma categoria recorrente: julgamento prejudicado por perda de objeto. O fenômeno da "ameaça do habeas corpus" - quando a impetração serviu como uma alavanca para a regularização, pelo menos parcial, do processo, por parte do magistrado de primeiro grau - pode ter aparecido nessa categoria. A simples impetração do HC, nessas situações, pode ter funcionado como um instrumento de pressão para que a autoridade coatora corrigisse a situação de constrangimento ilegal. Nesses casos, o HC, apesar de formalmente ter sido julgado prejudicado, alcançou de certo modo seu objetivo, o que deslocaria seu enquadramento para a categoria de ações exitosas. Contudo, à época não foi possível analisar os autos completos de cada processo julgado prejudicado para verificar essa situação, que se reiterada poderia modificar os dados finais. Outra situação possível é que os casos de perda de objeto se devam a eventual demora no julgamento do próprio habeas corpus. Essa inércia judicial sinalizaria uma dupla penalização, porque nesses casos o paciente não apenas enfrenta o constrangimento ilegal noticiado pelo $\mathrm{HC}$, como também sequer teve um pronunciamento célere do Tribunal. Contudo, mais uma vez, isso não foi pensado à época.

Em quinto lugar, variáveis como o perfil dos impetrantes (advogados, Defensoria Pública, leigos) e dos pacientes (raça, gênero, idade) não foram mapeadas, apesar de existirem diversos estudos empíricos que indicam a influência de questões extrajurídicas nas decisões judiciais. Para facilitar o processo de coleta de dados, é possível alimentar o conjunto de variáveis pelo Programa SPSS, software estatístico para as ciências sociais (FIELD, 2009). Contudo, somente se conheceu o programa após a finalização da pesquisa. 
Por fim, enriqueceria a pesquisa buscar amostras comparativas. Afinal, o objetivo era estabelecer inferências descritivas sobre a efetividade do habeas corpus enquanto garante da liberdade que parametriza a violência ínsita ao poder de punir do Estado. Aprendendo sobre como os Desembargadores da Câmara Criminal do TJSE julgavam os pedidos de HC, buscava-se aprender sobre quão efetiva é a ordem de HC na tutela da liberdade das pessoas. Cobrir um único tribunal, contudo, enfraquece as conclusões pelo risco de que o tribunal escolhido tenha um perfil homogêneo (muito garantista ou pouco garantista, por exemplo). Nesses termos, uma pesquisa comparativa entre tribunais daria maior credibilidade às conclusões da pesquisa.

\section{Considerações finais}

Esses são exemplos de "pontos cegos" ante os quais qualquer pesquisador, em qualquer pesquisa empírica em direito que trabalhe com coleta de dados e com seu tratamento, precisa desenvolver autoconsciência, de modo a conferir credibilidade científica aos seus dados. Por essa razão, as inferências feitas na pesquisa original sobre a efetividade do habeas corpus pecam por falhas metodológicas, que somente ficaram visíveis para o pesquisador no momento da apresentação dos dados. Eis, então, a importância da orientação de Epstein e King (2013, p. 42), já mencionada anteriormente: o percurso metodológico deve ser detalhado ao máximo, e todas as decisões do percurso devem ser reveladas para o leitor, pois somente assim este terá condições de medir o grau de representatividade da amostra em face da população. Quanto maior esse grau de representatividade, tanto mais qualificado é o nível das inferências propostas na busca de achados válidos sobre a prática judicial dos institutos da dogmática jurídica, como o habeas corpus.

\section{Referências bibliográficas}

CASTRO, Alexandre Samy de. O método quantitativo na pesquisa de direito. In:

MACHADO, Maíra Rocha (org.). Pesquisar empiricamente o direito. São Paulo: Rede de Pesquisa Empírica em Direito, 2017.

EPSTEIN, Lee; KING, Gary. Pesquisa empírica em direito: as regras de inferência. São Paulo: Direito GV, 2013.

FERRAZ JUNIOR, Tercio Sampaio. Introdução ao estudo do direito: técnica, dominação, decisão. 7. ed. São Paulo: Atlas, 2013.

FIELD, Andy. Descobrindo a estatística usando o SPSS. 2. ed. Porto Alegre: Artmed, 2009. 
KOERNER, Andrei. Habeas corpus, prática judicial e controle social no Brasil (1841-1920). São Paulo: IBCCrim, 1999.

NOBRE, Marcos et al. O que é pesquisa em Direito? São Paulo: Quartier Latin, 2005.

OLIVEIRA, Luciano. Não fale do Código de Hamurábi! A pesquisa sócio-jurídica na pósgraduação de Direito, sem data. Disponível em:

https://www.uniceub.br/media/180293/Texto_IX.pdf.Acesso em: 12 set. 2018.

REGINATO, Andrea Depieri de Albuquerque; ALVES, Robson Cosme de Jesus. O ementário jurisprudencial como fonte de pesquisa: uma análise crítica a partir dos dados obtidos no estudo "A prática judicial do habeas corpus em Sergipe (1996-2000)". Revista de Estudos Empíricos em Direito, vol. 1, n. 1, jan. 2014, p. 140-153.

SANTOS, Thandara (org.). Levantamento nacional de informações penitenciárias: INFOPEN Atualização - Junho de 2016. Brasília: Ministério da Justiça e Segurança Pública, Departamento Penitenciário Nacional, 2017.

VERONESE, Alexandre. Considerações sobre o Problema da Pesquisa Empírica em Direito e sua Baixa Integração na Área de Direito: A Tentativa de uma Perspectiva Brasileira a partir da Avaliação dos Cursos de Pós-Graduação do Rio de Janeiro. Revista da Procuradoria-Geral do Estado de Mato Grosso do Sul, Campo Grande, 2013, p. 197-228. 